\title{
Significant underestimate of gaseous Methanesulfonic Acid (MSA) over Southern Ocean
}

\author{
Jinpei Yan $^{* 1,2}$, Jinyoung Jung ${ }^{3}$, Miming Zhang ${ }^{1,2}$, Suqing Xu${ }^{1,2}$, Qi Lin ${ }^{1,2}$, Shuhui Zhao ${ }^{1,2}$, Liqi \\ Chen $^{* 1,2}$ \\ 1 Key Laboratory of Global Change and Marine-Atmospheric Chemistry, MNR, Xiamen 361005, China; \\ 2 Third Institute of Oceanography, Ministry of Natural Resources, Xiamen 361005, China; \\ 3 Korea Polar Research Institute, 26 Songdomirae-ro, Yeonsu-gu, Incheon 21990, Republic of Korea
}

Corresponding author: Jinpei Yan, E-mail address: jpyan@tio.org.cn

The supplementary information contains 10 pages, including 1 table and 7 figures. The table and figure captions are listed as follow:

Tab. S1 Gaseous and particulate MSA levels in different regions;

Fig. S1 Gases and aerosols monitoring system using in this study;

Fig. S2 Calibration curves of MSA, chloride, sulfate and sodium for IGAC monitoring system;

Fig. S3 Time series of particulate sodium and sulfate during the observation cruise;

Fig. S4 Time series of $\mathrm{MSA}_{\mathrm{g}}, \mathrm{MSA}_{\mathrm{p}}$, nss- $\mathrm{SO}_{4}{ }^{2-}$, and the meteorological parameters during November 2017 to February 2018;

Fig. S5 Spatial distributions of sea ices and Chlorophyll-a concentrations;

Fig. S6 Time series of the ratios of $\mathrm{MSA}_{\mathrm{g}}$ to $\mathrm{MSA}_{\mathrm{p}}$ during the whole cruise;

Fig. S7 Correlation between $\mathrm{MSA}_{\mathrm{g}}$ to nss- $\mathrm{SO}_{4}{ }^{2-}$ ratios and $\mathrm{MSA}_{\mathrm{T}}$ to nss- $\mathrm{SO}_{4}{ }^{2-}$ ratios. 
Tab. S1 Gaseous and particulate MSA levels in different regions

\begin{tabular}{ccccccccc}
\hline \multirow{2}{*}{ Region } & Longitude & Latitude & $\mathrm{MSA}_{\mathrm{g}(\mathrm{min})}$ & $\mathrm{MSA}_{\mathrm{g}(\mathrm{max})}$ & $\mathrm{MSA}_{\mathrm{g}(\mathrm{Avg} .)}$ & $\mathrm{MSA}_{\mathrm{p}(\mathrm{min})}$ & $\mathrm{MSA}_{\mathrm{p}(\mathrm{max})}$ & $\mathrm{MSA}_{\mathrm{p}(\mathrm{Avg} .)}$ \\
\cline { 2 - 8 } & $\left({ }^{\circ} \mathrm{E}\right)$ & $\left({ }^{\circ} \mathrm{S}\right)$ & $(\mathrm{pptv})$ & $(\mathrm{pptv})$ & $(\mathrm{pptv})$ & $\left(\mathrm{ng} \cdot \mathrm{m}^{-3}\right)$ & $\left(\mathrm{ng} \bullet \mathrm{m}^{-3}\right)$ & $\left(\mathrm{ng} \bullet \mathrm{m}^{-3}\right)$ \\
\hline Leg I & $76-177$ & $43-75$ & - & 24.5 & $5.9 \pm 4.7$ & 14.6 & 392.6 & $45.5 \pm 32.0$ \\
Leg II & $72-185$ & $43-78$ & - & 13.0 & $2.4 \pm 0.7$ & 0.3 & 165.4 & $33.7 \pm 24.8$ \\
MA1 & 173 & $43-51$ & 12.7 & 24.4 & $19.5 \pm 5.2$ & 73.2 & 167.0 & $99.6 \pm 22.9$ \\
MA2 & 172 & $64-69$ & 3.9 & 24.5 & $11.7 \pm 5.1$ & 49.5 & 392.6 & $84.0 \pm 38.3$ \\
MA3 & $125-142$ & 63 & 3.5 & 5.0 & $4.2 \pm 0.5$ & 50.8 & 95.0 & $61.7 \pm 16.3$ \\
MA4 & $85-93$ & 61.5 & 2.6 & 3.3 & $2.9 \pm 0.2$ & 43.3 & 144.9 & $57.4 \pm 24.6$ \\
MA5 & $170-185$ & $68.2-77.8$ & 1.4 & 4.0 & $2.4 \pm 0.6$ & 57.4 & 165.4 \\
MG1 & $163-177$ & $72-75$ & 5.0 & 21.4 & $6.7 \pm 2.2$ & 20.8 & 75.0 & $38.4 \pm 21.9$ \\
MG2 & $101-106$ & 62 & 4.8 & 5.7 & $5.3 \pm 0.3$ & 36.7 & 71.8 \\
\hline
\end{tabular}


Fig. S1 Gases and aerosols monitoring system. An underway biogenic gases and aerosols monitoring system were employed on the R/V "Xuelong" to carried out the observation in the SO. An In-situ Gas and Aerosol Composition monitoring system was used to determine the gaseous and aerosol water-soluble ions. A Single Particle Aerosol Mass Spectrometer was used to determine the particle size distribution and chemical compositions.

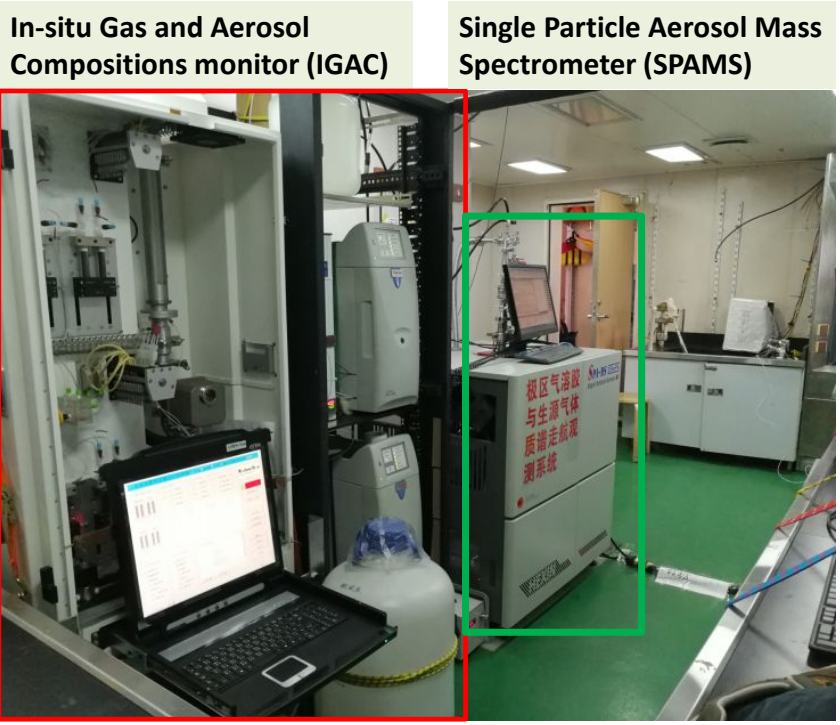




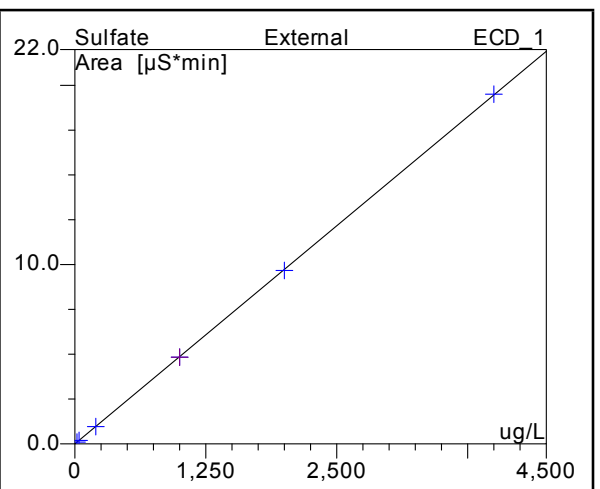
$\left(r^{2}=0.998\right)$.

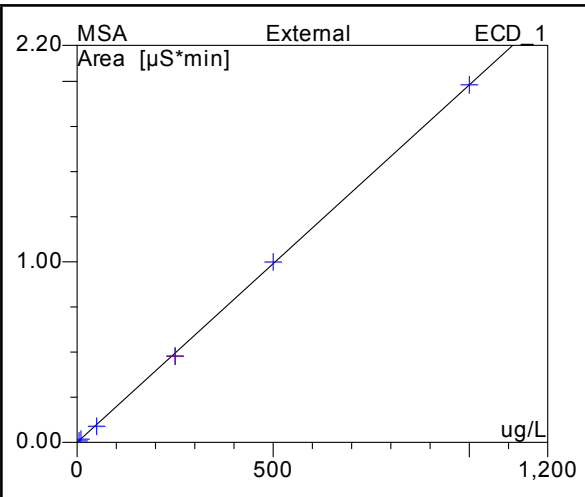

Fig.S2 Calibration curves of MSA, chloride, sulfate and sodium for IGAC monitoring system. (a) Six out of eight concentrations of standard solutions (0.1-1000 ug/L) were selected for MSA calibration $\left(\mathrm{r}^{2}=0.998\right)$; (b) Six out of eight concentrations of standard solutions $(0.1-2000 \mathrm{ug} / \mathrm{L})$ were selected for Chloride calibration $\left(r^{2}=0.997\right)$; (c) Six out of eight concentrations of standard solutions (0.1-4000 ug/L) were selected for Sulfate calibration $\left(\mathrm{r}^{2}=0.997\right)$; (d) Six out of eight concentrations of standard solutions $(0.1-2000 \mathrm{ug} / \mathrm{L})$ were selected for Sodium calibration
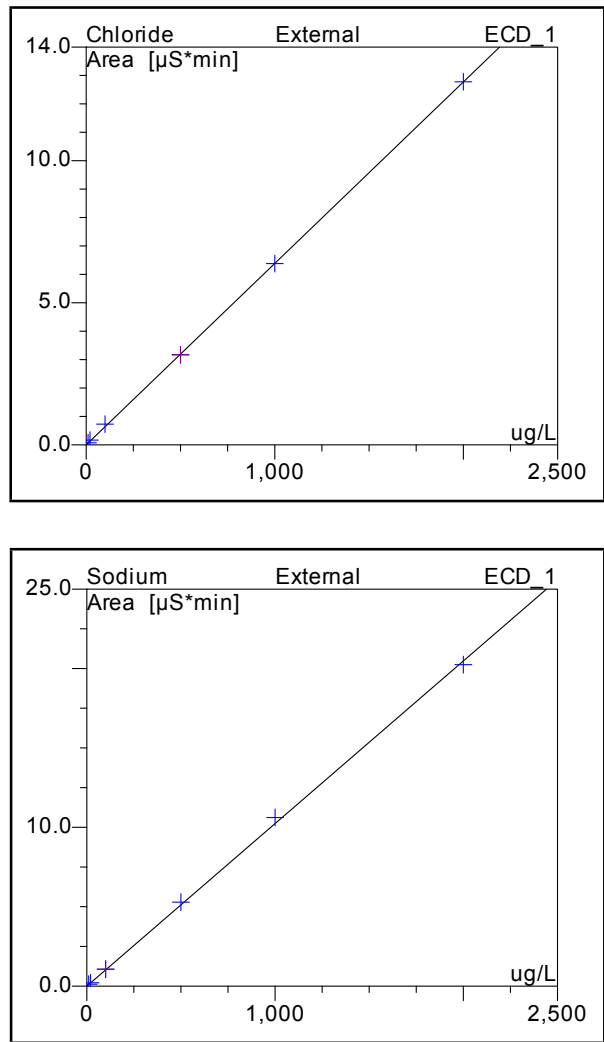
Fig. S3 Time series of particulate sodium and sulfate during the observation cruise.

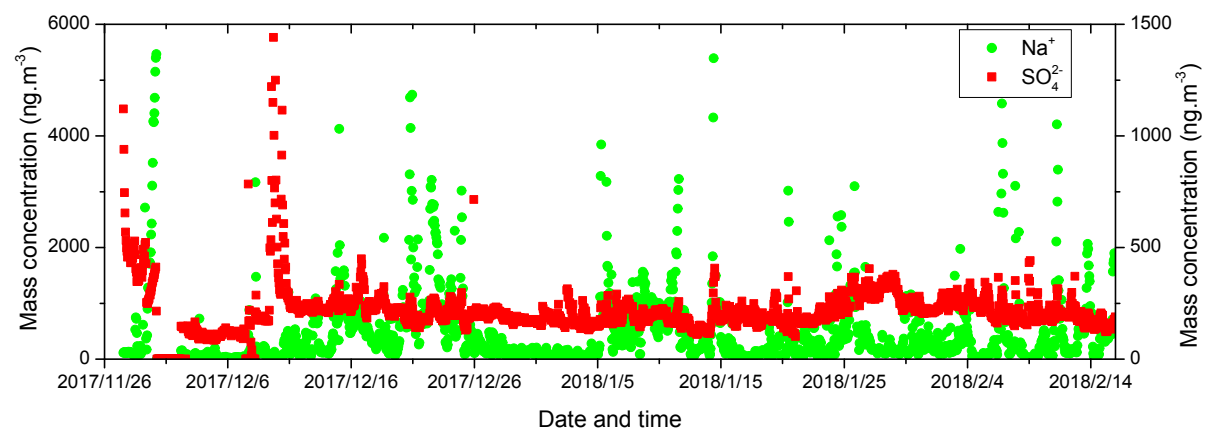


Fig. S4 Time series of gaseous and particulate MSA, nss-SO ${ }_{4}^{2-}$, and meteorological parameters during Nov. 2017 to Feb. 2018. (a) Temporal distributions of gaseous and particulate MSA; (b) Temporal distribution of nss- $\mathrm{SO}_{4}^{2-}$; (c) Temperature and $\mathrm{RH}$; (d) Wind speed and directions.

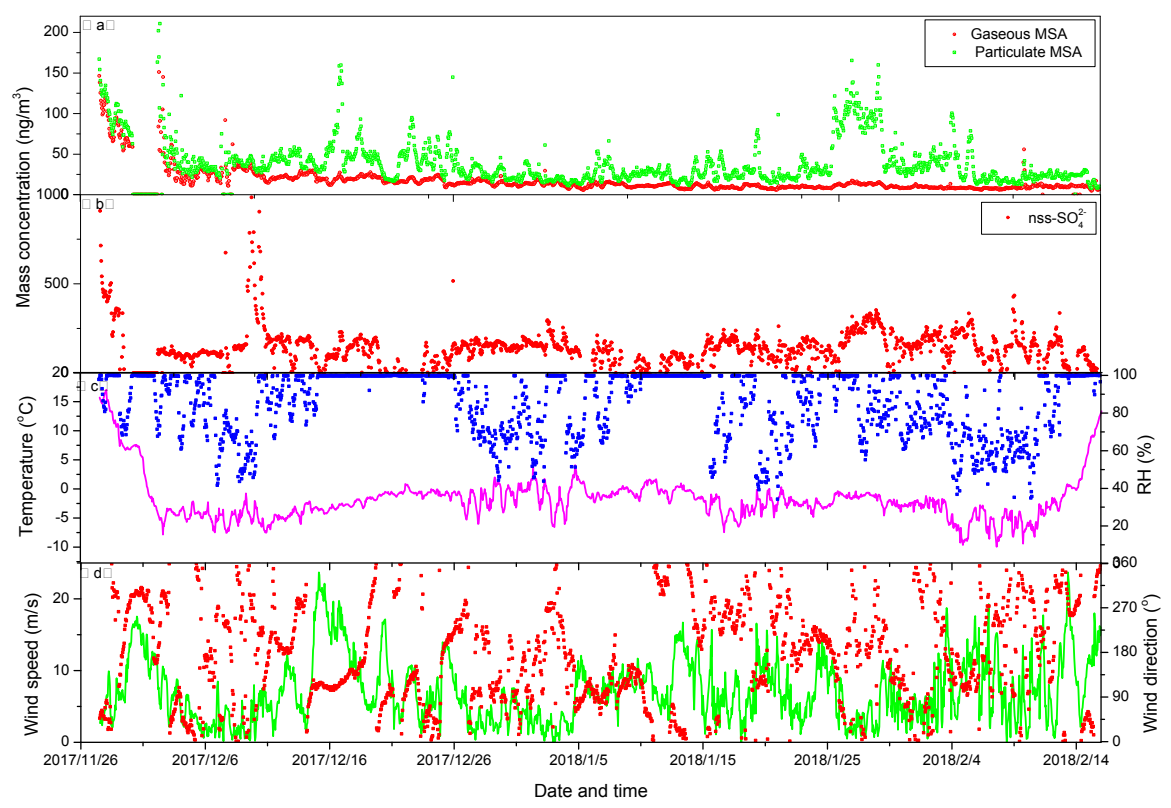


Fig. S5 Spatial distributions of sea ice and Chl-a concentrations. (a) Average sea ice during 4 to 14 December, 2017; (b) Average sea ice during 25 January to 4 February, 2018; (c) Mean Chl-a concentrations during 4 to 14 December, 2017; (d) Mean Chl-a concentrations during 25 January to 4 February, 2018. The Spatial distributions of sea ice and Chl-a concentrations in this figure were created with Ocean Data View (Ref.S1 and S2).
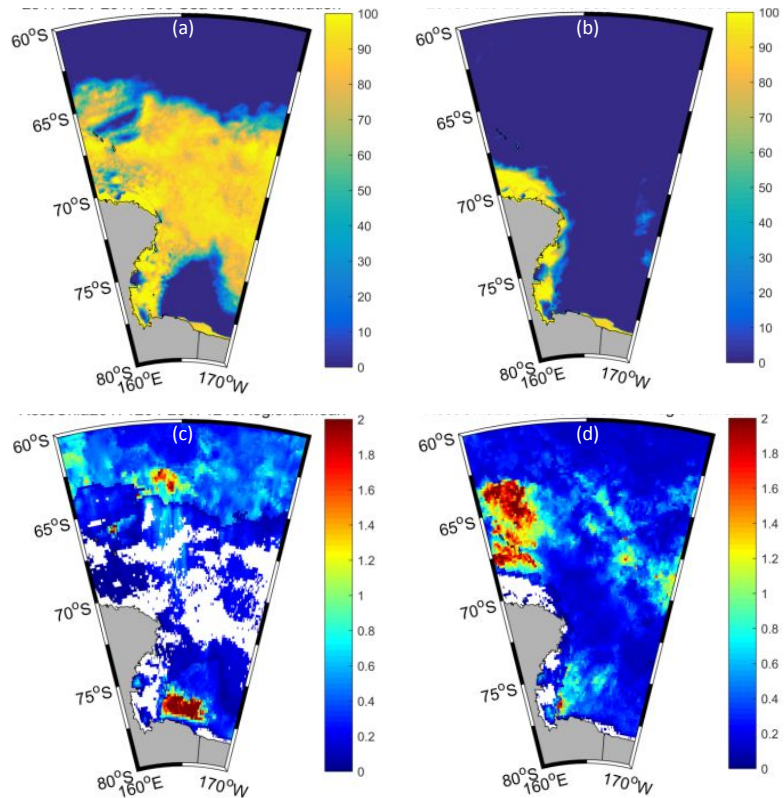
59 Fig. S6 Time series of the ratios of $\mathrm{MSA}_{\mathrm{g}}$ to $\mathrm{MSA}_{\mathrm{p}}$ during the whole cruise.

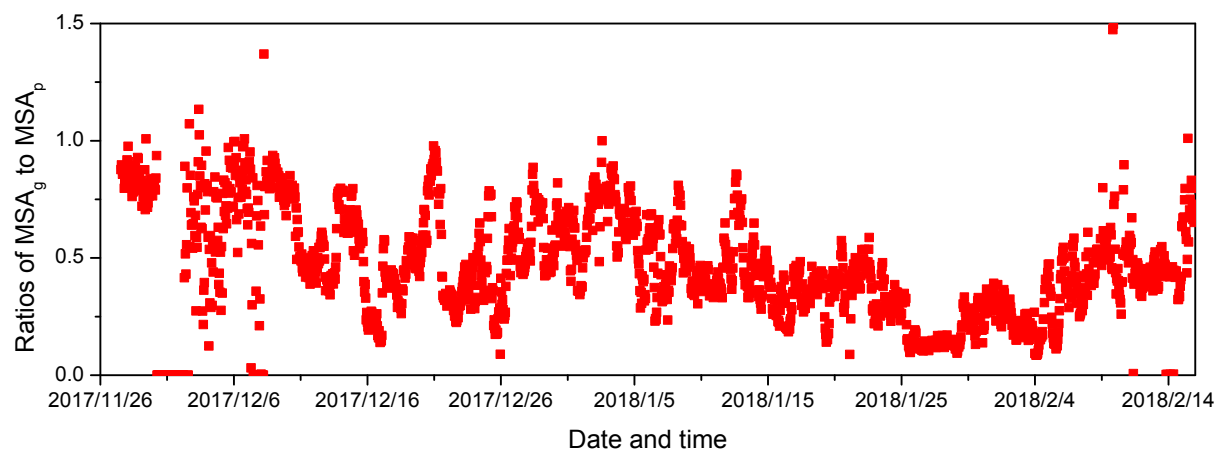

60

SB 
61 Fig. S7 Correlation between $\mathrm{MSA}_{\mathrm{g}}$ to nss- $\mathrm{SO}_{4}{ }^{2-}$ ratios and total $\mathrm{MSA}_{\mathrm{T}}$ to nss- $\mathrm{SO}_{4}{ }^{2-}$ ratios. $\mathrm{An}$ 62 intensity positive correlation between $\mathrm{R}_{\mathrm{p}}$ and $\mathrm{R}_{\mathrm{T}}\left(\mathrm{r}^{2}=0.985\right)$ was observed, with a slope of 0.693 . 63 The ratios of MSA to nss- $\mathrm{SO}_{4}{ }^{2-}$ were reduced by about $30 \%$ without $\mathrm{MSA}_{\mathrm{g}}$.

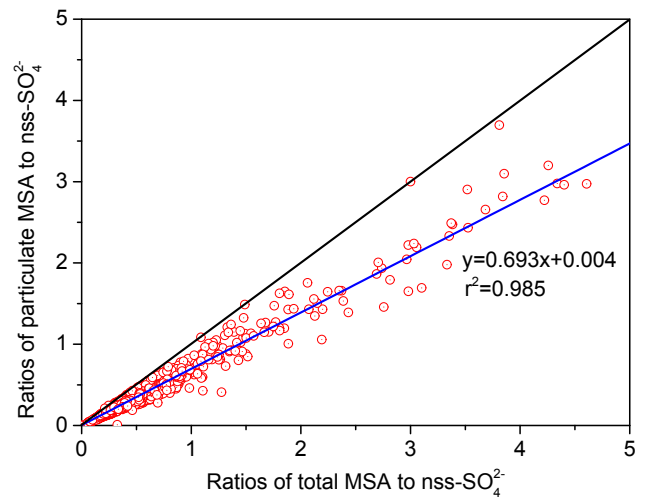


References

67

S1. Schlitzer, R. Ocean Data View, odv.awi.de, 2015.

68 S2. Schlizer, R. Interactive analysis and visualization of geosciences data with Ocean Data view. Computers 69 Geosciences. 2002, 28, 1211-1218.

70 